Annals of International Medical and Dental Research

E-ISSN: 2395-2822 | P-ISSN: 2395-2814

Vol-8, Issue-1 | January-February 2022

DOI: $10.53339 /$ aimdr.2022.8.1.43

Page no- 341-349 | Section- Research Article (Paediatrics)

\title{
Oxygen Saturation in Neonate after Birth
}

\section{Ajmery Sultana Chowdhury ${ }^{1 *}$, Tashmin Farhana ${ }^{2}$, Farhana Afroze ${ }^{3}$, Parisa Marjan ${ }^{4}$, Amena Akter ${ }^{5}$, M. A. Mannan6, Sharmin Akter ${ }^{7}$}

1Junior Consultant, Department of Paediatrics and NICU, Labaid Specialized Hospital, Dhaka, Bangladesh.

Email: ajmery_chowdhury@yahoo.com Orcid ID: 0000-0002-6134-7695

${ }^{2}$ Clinical Stuff, Department of NICU, Asgar Ali Hospital, Dhaka, Bangladesh. Email: tashminmasha2412@gmail.com Orcid ID: 0000-0002-4118-6097

${ }^{3}$ Assistant Professor, Department of Paediatric And Neonatology, Enam Medical College, Savar, Dhaka, Bangladesh. Email: farhana_nicu@yahoo.com

Orcid ID: 0000-0002-4118-6097

4Junior Consultant, Department of Paediatric Gastroenterology, Bangabandhu Sheikh Mujib Medical University (BSMMU), Dhaka, Bangladesh.

Email: marjanparisa@gmail.com

Orcid ID: 0000-0002-4118-6097

5Senior Registrar, Department of Paediatric Nephrology), Gonoshasthaya Samaj Vittik Medical College, Savar, Dhaka, Bangladesh.

Email: amina.nupur43@gmail.com

Orcid ID: 0000-0002-6134-7695

6Professor, Department of Neonatology, Bangabandhu Sheikh Mujib Medical University, Shahbag, Dhaka, Bangladesh.

Email: drmannan64@gmail.com

Orcid ID: 0000-0002-6134-7695

7Medical Assistant, E-Z Medical Care, 85-50 118th Street, Kew Gardens, NY11415, United States.

Email: sharminakter11@gmail.com

Orcid ID: 0000-0002-4446-681X

${ }^{*}$ Corresponding author

Received: 24 October 2021

Revised: 16 November 2021

Accepted: 25 November 2021

Published: 22 December 2021

\section{Abstract}

Background: Oxygen saturation measures the quantity of haemoglobin in the blood that is saturated with oxygen. Hemoglobin is a component of red blood cells that binds oxygen and transports it to outlying tissues. Oxygen is commonly used throughout the world in neonatal units. Injudicious use of Oxygen may not maintain appropriate oxygen status rather can lead to hypoxemia or hyperoxemia, both of the conditions are injurious to neonatal health. Objective: To assess the oxygen saturation in neonate after birth. Methods: A cross-sectional study conducted in the Department of Neonatology BSMMU, Shahbag, Dhaka, Lab Aid Specialized Hospital, Dhaka, Bangladesh from October 2013 to March 2014. A total 317 patients were selected according to selection criteria. The parents were interviewed with a specific pre-designed and pre-tested questionnaire and some information were gathered by document review. All neonate both term and late preterm ( $>34$ weeks) who would not be anticipated for resuscitation was included. Results: A total 317 neonate were selected according to selection criteria. Among the study subjects more than half were male (57.1\%). Rests were female $(42.9 \%)$. Average gestational age of the study subjects was $37.47 \pm$ 1.16 (SD) with the range of 34-40. On the other hand average birth weight was $2.88 \pm 0.46$ (SD) with the minimum birth weight $2.0 \mathrm{~kg}$ and maximum weight $4.2 \mathrm{~kg}$. Illustrates the median (IQR) heart rate from one to ten min for preterm versus term births. At one to three minutes and at five minutes after birth preterm infants had significantly lower SpO2 measurements. From six to 10 minutes after birth and four minutes after birth there was no significant difference between $\mathrm{SpO} 2$ measurements for mode of delivery. Paired sample $\mathrm{t}$ test showed that average SpO2 was less in 1 minute[88.42 $\pm 4.8(\mathrm{SD})]$ than in 5 minute [94.25 $\pm 3.5(\mathrm{SD})]$ and statistically this differences were highly significant $(t=24.44, p=0.000)$. Pearson correlation showed high positive correlation $(p=0.000)$ and correlation co-efficient $r=0.479$. Correlation was significant at the 0.01 level. Conclusion: It is "normal" to have low oxygen saturation measurements in the first minutes after birth. It takes time for infants to reach oxygen saturation levels described as "normal" in the later postnatal period. Oxygen saturation increased with time i.e., it was more in 5 minutes than in 1 minute and similarly more in 10 minutes than in 5 minutes. Conversely heart rate was found more in one minute than to five and ten minutes. Oxygen saturation was $\geq 90 \%$ within 3 to 4 minutes. Significant changes were found in Oxygen saturation by mode of delivery in three minutes \& in heart rate by two minutes after birth. At one to ten minutes after birth preterm infants had lower $\mathrm{SpO} 2$ measurements. 
Annals of International Medical and Dental Research

E-ISSN: 2395-2822 | P-ISSN: 2395-2814

Vol-8, Issue-1 | January-February 2022

DOI: 10.53339/aimdr.2022.8.1.43

Page no- 341-349 | Section- Research Article (Paediatrics)

Keywords:- Pulse Oximetry, Oxygen Saturation, Newborn, Birth Weight.

\section{INTRODUCTION}

Oxygen saturation measures the quantity of haemoglobin in the blood that is saturated with oxygen. Hemoglobin is a component of red blood cells that binds oxygen and transports it to outlying tissues. A healthy baby that is born full term should have oxygen saturations of 95 to 100 percent. Normal values for preterm infant oxygen saturations are 84 to 90 percent. Pulse oxymetry in the delivery room have documented that it takes more than 5minutes for a new born undergoing normal postnatal transition to attain an oxygen saturation $>80 \%$ and almost 10 minutes to reach $90 \%$. A dministering $100 \%$ oxygen to a spontaneously breathing neonate based only on visual assessment of cyanosis may be unnecessary and lead to potentially harmful hyperoxia. All the newborns are "cyanotic" at birth; in the process of postnatal adaptation, a normal newborn undergoes a period of transitional physiological cyanosis.[1] During the first few minutes of life, oxygen saturation (saturation by pulse oxymetry, SpO2) increases from intrapartum levels of $30-40 \%$.[2] Pulse oxymetry if routinely used in intensive care, gives continuous accurate measures of Heart Rate and Oxygen Saturation. As demographic data like(maturity, birth weight, gestational age, marenal age, maternal nutrition, socioeconomic status, mode of delivery, maternal problem during antinatal and perinatal period, number of gestation, foetal condition),genetic and environmental factor are different from other countries in Bangladesh. The transition from fetus to newborn is a complex physiological process.
There is growing interest in the use of pulse oxymetry to assess the condition of infants immediately after birth.[3] In the first day of life bidirectional shunting through ductus may occur and this is often proposed as an explanation for a poor PO2.If significant bidirectional or right to left shunting is occurring then blood perfusing the right subclavian and carotid arteries could have a substantially higher oxygen content then that being measured.[4,5] Injudicious use of Oxygen may not maintain appropriate oxygen status rather can lead to hypoxemia or hyperoxemia ,both of the conditions are injurious to neonatal health.[6] There are many monitoring system of oxygen of which pulse oxymetry is referred as $5^{\text {th }}$ vital sign. Oxygen should be supplemented only when it is indicated.[6] Pulse oxymetry is now the predominant method of oxygen monitoring. It is based on the principle that oxygenated haemoglobin absorbs light in the infrared region of the spectrum (850-1000nm) while deoxygenated haemoglobin absorbs light in the visible red band $(600-750 \mathrm{~nm})$. The ratio of light absorbed at two different wave lengths correlates with the proportions of oxygenated and deoxygenated haemoglobin in the tissue.

\section{MATERIAL AND METHODS}

A cross-sectional study conducted in the Department of Neonatology BSMMU, Shahbag, Dhaka, Lab Aid Specialized Hospital, Dhaka, Bangladesh from October 2013 to March 2014. The study was oxygen saturation immediately after birth and to describe changes in heart rate immediately after birth. A total 317 patients were selected according to 
Annals of International Medical and Dental Research

E-ISSN: 2395-2822 | P-ISSN: 2395-2814

Vol-8, Issue-1 | January-February 2022

DOI: 10.53339/aimdr.2022.8.1.43

Page no- 341-349 | Section- Research Article (Paediatrics)

selection criteria. The parents were interviewed with a specific pre-designed and pre-tested questionnaire and some information were gathered by document review. All neonate both term and late preterm ( $>34$ weeks) who would not be anticipated for resuscitation was included.

\section{Inclusion criteria:}

All neonate both term and late preterm (>34week) who would not be anticipated for resuscitation was included.

\section{Exclusion criteria:}

Neonates who were received supplemental oxygen or assisted ventilation, baby of known case of $\mathrm{Rh}$ negative mother with significant antibody titre $(\geq 1: 64)$. When we would be unable to obtain oxymetry data and whose parents was not give consent was excluded.

\section{Variable Outcome:}

Main outcome variable were Oxygen Saturation and Heart Rate. Confounders were Birth weight, mode of delivery, maternal age, gestational age, motion artifact, presence of vernix, low perfusion, oedema, high ambient light, large infants, cracked/wrinkled skin, acrocyanosis.

\section{Operational definition:}

Term Infant: An infant born between the end of the 37 week and the end 41weeks and 6days of gestation.

Late preterm infant: A late preterm infant is a premature baby born between 34 and 36 weeks gestational age. This is relatively close to full term, which is 37 weeks or greater.

Oxygen saturation: Oxygen saturation measures the quantity of hemoglobin in the blood that is saturated with oxygen. Hemoglobin is a component of red blood cells that binds with oxygen and transports it to outlying tissues. Oxygen saturation is measured by pulse oximetry.[6]

Desaturation (Hypoxemia): Desaturation may refer to: In pulse oximetry, the condition of a low blood oxygen concentration.

Pulse oximeter: A noninvasive device that measures the arterial blood oxygen saturation by means of a sensor attached to the hand.

Heart Rate in newborn: The normal heart rate is $100-180$ beats/ $\min$ in the newborn.

Hypoxia: The term hypoxia is a condition where the tissues are not oxygenated adequately, usually due to an insufficient concentration of oxygen in the blood. Hypoxialiterally means "low oxygen $(<95 \%$ in term and $<84 \%$ in preterm)", but is defined as deficiency in the amount of oxygen of that reaches the tissues of the body.

Statistical analysis: After collection all the data were checked and edited. Then data were entered into the computer with the help of software SPSS for windows programmed version 16.0. After frequency run, data were cleaned and frequencies were checked. An analysis plan was developed keeping in view with the objectives of the study. Cross tabulation was prepared and a comparison had been made between, Data was presented as means (SD) and analyzed with 2-tailed tests 
Annals of International Medical and Dental Research

E-ISSN: 2395-2822 | P-ISSN: 2395-2814

Vol-8, Issue-1 | January-February 2022

DOI: 10.53339/aimdr.2022.8.1.43

Page no- 341-349 | Section- Research Article (Paediatrics)

when normally distributed. Median and interqurtile ranges $(\mathrm{IQR}=\mathrm{Q} 3-\mathrm{Q} 1)$ was provided and analyzed with nonparametric tests (2tailed Mann-Whitney $U$ test) when the distribution of the variable was skewed. The median SpO2 values (IQR) at 1,2,3,4 ...and 10 minutes, respectively was provided. Multivariate regression analysis was used to analyze. Potential confounding variable contributing to the primary end point (time taken for $\mathrm{SPO} 2>90 \%)$. A P value of $<.05$ was considered as statistically significant. Median, quartiles, range, outliers and extrerme values, of $\mathrm{SpO} 2$ and Heart Rate at 10 minutes from birth was shown by: mode of delivery; maturity, maternal analgesia and maternal anaesthesia. Mann Whitney $U$ test was used to compare data in minutes (median [IQR] for neonate to attain $\mathrm{SpO} 2>75 \%$ and $>90 \%$ by mode of delivery, presence of labour and by gestational age $(<37 \mathrm{wk}$ versus $\geq 37 \mathrm{wk})$. Quality of data was obviously maintained. Regular instruction from the supervisor was taken to control the quality of Data. All the patients was examined carefully. Regular follow-up from each patient was strictly done. Every data was kept confidential.

\section{RESULTS}

A cross sectional study was carried out to construct a simple reference range of heart rate and oxygen saturation in healthy neonate immediately after birth using pulse oxymeter. A total 317 neonate were selected according to selection criteria. Among the study subjects more than half were male $(57.1 \%)$. Rests were female $(42.9 \%)$ [Table 1$]$.
The mode of delivery was mostly LUCS (96.6\%). Only $5.4 \%$ cases it was NVD [Figure $1]$.

Average gestational age of the study subjects was 37.47 \pm 1.16 (SD) with the range of 34-40. On the other hand average birth weight was $2.88 \pm 0.46$ (SD) with the minimum birth weight $2.0 \mathrm{~kg}$ and maximum weight $4.2 \mathrm{~kg}$ [Table 2].

[Table 3] showed that differences of oxygen saturation in three minutes after delivery were statistically significant.

[Table 4] illustrates the median (IQR) heart rate from one to ten min for preterm versus term births. At one to three minutes and at five minutes after birth preterm infants had significantly lower SpO2 measurements. From six to 10 minutes after birth and four minutes after birth there was no significant difference between SpO2 measurements for mode of delivery.

Paired sample $\mathrm{t}$ test showed that average $\mathrm{SpO} 2$ was less in 1 minute[88.42 $\pm 4.8(\mathrm{SD})]$ than in 5 minute [94.25 $\pm 3.5(\mathrm{SD})]$ and statistically this differences were highly significant $(\mathrm{t}=24.44$, $\mathrm{p}=0.000)$. Pearson correlation showed high positive correlation $(p=0.000)$ and correlation co-efficient $r=0.479$. Correlation was significant at the 0.01 level [Figure 2].

Paired sample $\mathrm{t}$ test showed that average $\mathrm{SpO} 2$ was less in 5 minutes [94.25 $\pm 3.5(\mathrm{SD})]$ than in 10 minute [96.32 $\pm 3.2(\mathrm{SD})]$ and statistically this differences were highly significant $(t=12.07$, $\mathrm{p}=0.000)$. Pearson correlation showed high positive correlation $(p=0.000)$ and correlation co-efficient $r=0.606$. Correlation was significant at the 0.01 level [Figure 3]. 
Annals of International Medical and Dental Research

E-ISSN: 2395-2822 | P-ISSN: 2395-2814

Vol-8, Issue-1 | January-February 2022

DOI: 10.53339/aimdr.2022.8.1.43

Page no- 341-349 | Section- Research Article (Paediatrics)

Table 1: Sex distribution of the study subjects $(\mathrm{N}=317)$

\begin{tabular}{|l|l|l|}
\hline Sex & No. of the study subjects (N) & Percent (\%) \\
\hline Male & 181 & 57.1 \\
\hline Female & 136 & 42.9 \\
\hline Total & 317 & 100.0 \\
\hline
\end{tabular}

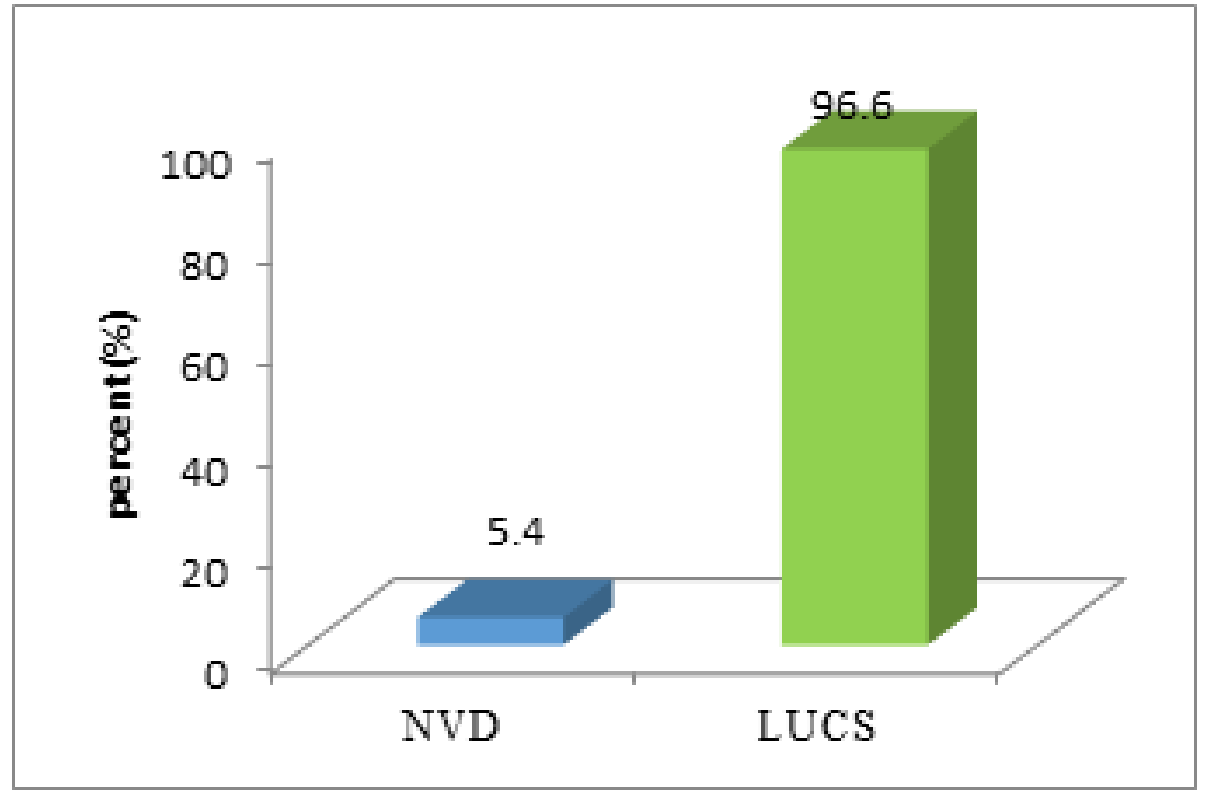

Figure 1: Mode of delivery.

Table 2: Average Gestational age and birth weight of the study subjects.

\begin{tabular}{|l|l|l|l|}
\hline Characteristics & Mean \pm SD & Minimum & Maximum \\
\hline Gestational age & $37.47 \pm 1.16$ & 34 & 40 \\
\hline Birth weight & $2.88 \pm 0.46$ & 2.0 & 4.2 \\
\hline
\end{tabular}

Table 3: Comparison of oxygen saturation measured by oxymeter between infants delivered by NVD and Caesarian section.

\begin{tabular}{|l|l|l|l|}
\hline Oxygen saturation & Mode of delivery & \multicolumn{2}{l|}{} \\
\hline Minutes from birth & SpO $^{2}$ Vaginal birth & SpO' Caesarian birth & p \\
\hline 1 minute & $86(85-89)$ & $86(85-93)$ & 0.283 \\
\hline 2 minute & $89(85-92)$ & $90(87-94)$ & 0.361 \\
\hline 3 minute & $88(88-90)$ & $92(89-96)$ & 0.025 \\
\hline 4 minute & $90(90-93)$ & $93(91-97)$ & 0.407 \\
\hline 5 minute & $92(91-96)$ & $94(92-97)$ & 0.207 \\
\hline 6 minute & $94(92-95)$ & $95(92-98)$ & 0.319 \\
\hline 7 minute & $92(92-97)$ & $95(92-98)$ & 0.290 \\
\hline
\end{tabular}


Annals of International Medical and Dental Research

E-ISSN: 2395-2822 | P-ISSN: 2395-2814

Vol-8, Issue-1 | January-February 2022

DOI: 10.53339/aimdr.2022.8.1.43

Page no- 341-349 | Section- Research Article (Paediatrics)

\begin{tabular}{|l|l|l|l|}
\hline 8 minute & $95(93-100)$ & $95(92-98)$ & 0.125 \\
\hline 9 minute & $98(93-99)$ & $96(94-99)$ & 0.607 \\
\hline 10 minute & $99(92-100)$ & $97(94-99)$ & 0.785 \\
\hline
\end{tabular}

Data are median (interquartile range)

Table 4: Comparison of heart rate measured by oxymeter between infants delivered by NVD and Caesarian section.

\begin{tabular}{|l|l|l|l|}
\hline \multirow{2}{*}{ Minutes from birth } & Heart Rate & Caesarian birth & $\mathbf{p}$ \\
\cline { 2 - 4 } & Vaginal birth & $157(150-160)$ & 0.150 \\
\hline 1 minute & $167(148-168)$ & $154(148-161)$ & 0.027 \\
\hline 2 minute & $163(149-172)$ & $156(148-162)$ & 0.057 \\
\hline 3 minute & $165(150-171)$ & $154(146-161)$ & 0.898 \\
\hline 4 minute & $160(142-160)$ & $154(146-161)$ & 0.277 \\
\hline 5 minute & $159(148-165)$ & $154(146-160)$ & 0.761 \\
\hline 6 minute & $155(146-163)$ & $154(144-162)$ & 0.558 \\
\hline 7 minute & $154(143-156)$ & $150(144-161)$ & 0.504 \\
\hline 8 minute & $155(141-168)$ & $150(143-158)$ & 0.967 \\
\hline 9 minute & $150(139-163)$ & $150(143-158)$ & 0.294 \\
\hline 10 minute & $148(143-165)$ & & \\
\hline
\end{tabular}

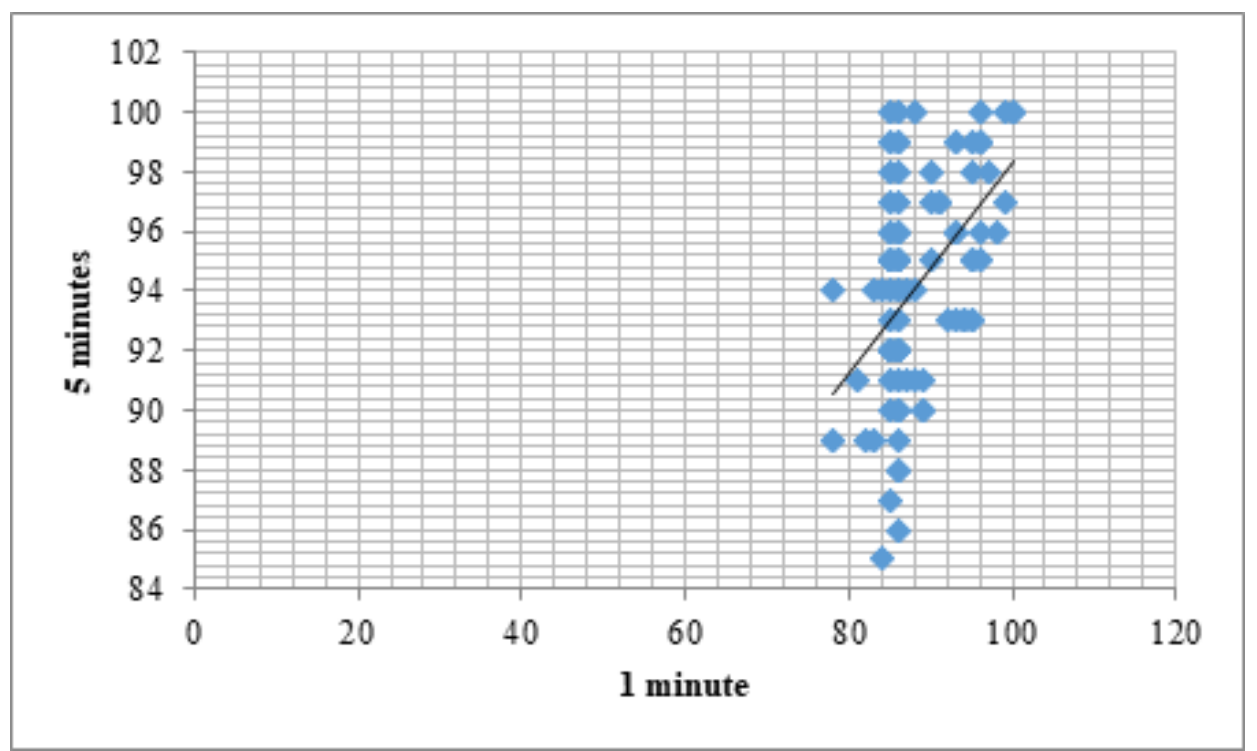

Figure 2: Scatter diagram showed positive correlation of SpO2 in 1 minute with SpO2 in five minutes. 
Annals of International Medical and Dental Research

E-ISSN: 2395-2822 | P-ISSN: 2395-2814

Vol-8, Issue-1 | January-February 2022

DOI: 10.53339/aimdr.2022.8.1.43

Page no- 341-349 | Section- Research Article (Paediatrics)

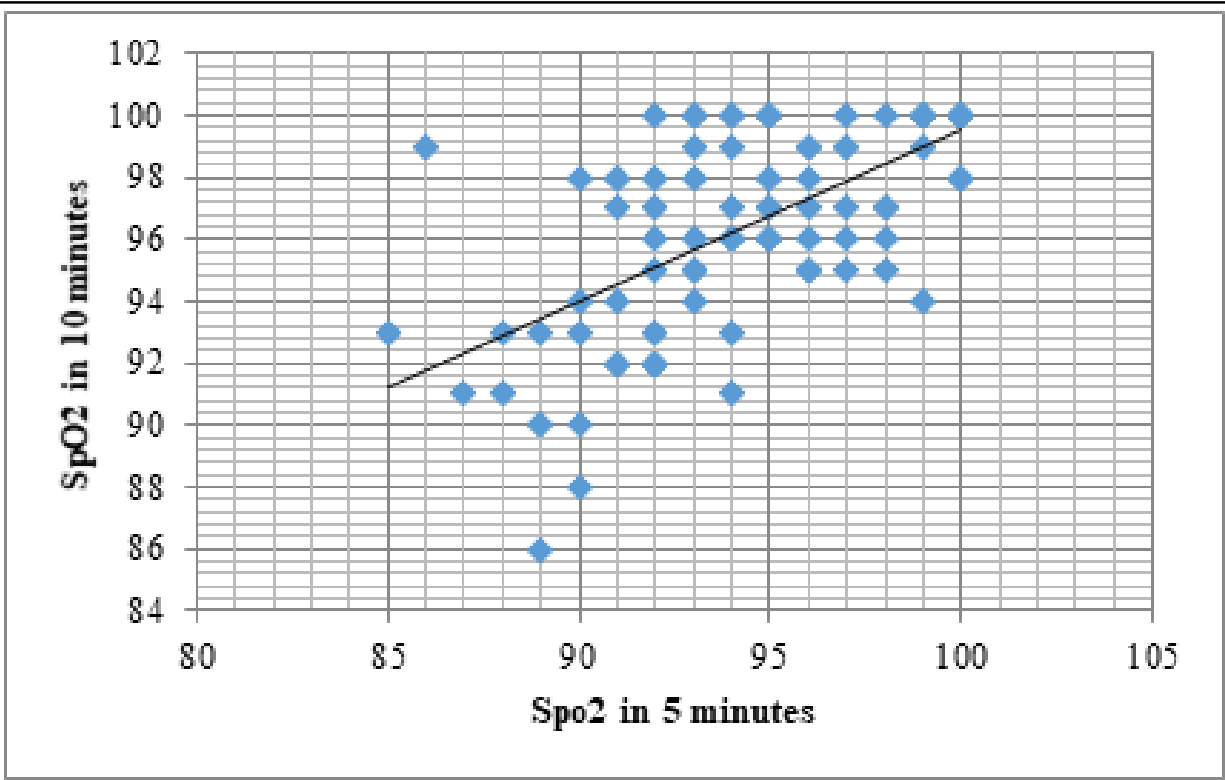

Figure 3: Scatter diagram showed positive correlation of $\mathrm{SpO} 2$ in 5 minutes with 10 minutes.

\section{DISCUSSION}

A cross sectional study was carried out to construct a reference range of heart rate and oxygen saturation in healthy neonate immediately after birth using pulse oxymeter. A total 317 neonate were selected according to selection criteria. Among the study subjects more than half were male $(57.1 \%)$. Rest were female $42.9 \%$ ). The mode of delivery was mostly LUCS (76.0\%). Only $24.0 \%$ cases it was NVD. Average gestational age of the study subjects was $37.47 \pm 1.16$ (SD) with the range of 34-40. On the other hand average birth weight was $2.88 \pm 0.46$ (SD) with the minimum birth weight $2.0 \mathrm{~kg}$ and maximum weight $4.2 \mathrm{~kg}$. We found that differences of oxygen saturation between NVD and caesarian birth in three minutes after delivery were statistically significant. This is consistent with the findings of Rabi, [] and Harris,[] and postulated that this difference was due to the increased amount of lung fluid after caesarean section which may interfere with transition to air breathing. In contrast other researchers found no significant difference in SpO2 measurements in infants born NVD versus caesarean births. [9] The latter group of studies had smaller samples and used older-generation pulse oximeter that may have contributed to their findings. This may also be related to more preterm infants being born via caesarean skewing the data because only $42 \%$ of preterm infants were born by NVD. This study compares the median (IQR) SpO2 measurements from 1 to $10 \mathrm{~min}$ for preterm ( $<37$ weeks gestation) versus term ( $\geq 37$ weeks gestation) infants. At one to ten minutes after birth preterm infants had lower SpO2 measurements. But these differences were not statistically significant. The median (IQR) heart rate from one to ten min for preterm versus term births. Pulse oximetry data can be obtained within 1 to 2 minutes after birth and gives a continuous, noninvasive measure of SpO2 and heart rate. Kamlin $\mathrm{CO}$ et al.10] reported that gestation and the presence of 
Annals of International Medical and Dental Research

E-ISSN: 2395-2822 | P-ISSN: 2395-2814

Vol-8, Issue-1 | January-February 2022

DOI: 10.53339/aimdr.2022.8.1.43

Page no- 341-349 | Section- Research Article (Paediatrics)

labor have an effect on SpO2 in the minutes after birth. Ruegger $C$ et al.[11] found that birth weight had a positive correlation to the difference between pre and post ductal values. Toth et al.[12] in his study, measured the pre and post ductal SpO2 with pulse oximeter of 50 vaginally born healthy term infants. At one to three minutes and at five minutes after birth preterm infants had significantly lower heart rate measurements. From six to 10 minutes after birth and four minutes after birth there was no significant difference between heart rate measurements for mode of delivery. In our study the differences of heart rate in two minutes after delivery were statistically significant. The median values were more in vaginal birth from 1 to 9 minutes. But median heart rate was more in 10 minutes in caesarian birth baby. But these differences were not statistically significant.

\section{REFERENCES}

1. Rabi Y, Yee W, Chen SY, Singhal N. Oxygen saturation trends immediately after birth. J Pediatr. 2006;148(5):590-4. doi: 10.1016/j.jpeds.2005.12.047.

2. Dawson JA, Davis PG, O'Donnell CP, Kamlin CO, Morley CJ. Pulse oximetry for monitoring infants in the delivery room: a review. Arch Dis Child Fetal Neonatal Ed. 2007;92(1):F4-7. doi: 10.1136/adc.2006.102749.

3. Kamlin CO, O'Donnell CP, Davis PG, Morley CJ. Oxygen saturation in healthy infants immediately after birth. J Pediatr. 2006;148(5):585-9. doi: 10.1016/j.jpeds.2005.12.050.

4. Clyman RI, Jobe A, Heymann M, Ikegami M, Roman C, Payne B, Mauray F. Increased shunt through the patent ductus arteriosus after surfactant replacement therapy. J Pediatr. 1982;100(1):101-7. doi: 10.1016/s0022-3476(82)80247-3.

\section{CONCLUSIONS}

A cross sectional study was carried out to construct a reference range of heart rate and oxygen saturation in healthy neonate immediately after birth using pulse oxymeter. It is "normal" to have low oxygen saturation measurements in the first minutes after birth. It takes time for infants to reach oxygen saturation levels described as "normal" in the later postnatal period. Oxygen saturation increased with time i.e., it was more in 5 minutes than in 1 minute and similarly more in 10 minutes than in 5 minutes. Conversely heart rate was found more in one minute than to five and ten minutes. Oxygen saturation was $\geq 90 \%$ within 3 to 4 minutes. Significant changes were found in Oxygen saturation by mode of delivery in three minutes \& in heart rate by two minutes after birth. At one to ten minutes after birth preterm infants had lower SpO2 measurements.

5. Rudolph AM, Drorbaugh JE, Auld PAM, et al. Studies on the circulation in the neonatal period. Paediatrics 1961; 27:551-66.

6. Finer N, Leone T. Oxygen saturation monitoring for the preterm infant: the evidence basis for current practice. Pediatr Res. 2009;65(4):375-80. doi: 10.1203/PDR.0b013e318199386a.

7. O'Donnell CP, Kamlin CO, Davis PG, Morley CJ. Obtaining pulse oximetry data in neonates: a randomised crossover study of sensor application techniques. Arch Dis Child Fetal Neonatal Ed. 2005;90(1):F84-5. doi: 10.1136/adc.2004.058925.

8. Liley HG, Mildenhall L, Morley P; Australian New Zealand Committee on Resuscitation. Australian and New Zealand Committee on Resuscitation Neonatal Resuscitation guidelines 2016. J Paediatr Child Health. 2017;53(7):621-627. doi: 10.1111/jpc.13522.

9. Dawson JA, Davis PG, O'Donnell CP, Kamlin CO, Morley CJ. Pulse oximetry for monitoring infants in the delivery room: a review. Arch Dis Child Fetal 
Annals of International Medical and Dental Research

E-ISSN: 2395-2822 | P-ISSN: 2395-2814

Vol-8, Issue-1 | January-February 2022

DOI: 10.53339/aimdr.2022.8.1.43

Page no- 341-349 | Section- Research Article (Paediatrics)

Neonatal doi:10.1136/adc.2006.102749

10. Kamlin CO, O'Donnell CP, Davis PG, Morley CJ. Oxygen saturation in healthy infants immediately after birth. J Pediatr. 2006;148(5):585-9. doi: 10.1016/j.jpeds.2005.12.050.

11. Rüegger C, Bucher HU, Mieth RA. Pulse oximetry in the newborn: is the left hand pre- or post-ductal?. BMC Pediatr. 2010;10:35. doi:10.1186/1471-2431-10-35
12. Toth B, Becker A, Seelbach-Göbel B. Oxygen saturation in healthy newborn infants immediately after birth measured by pulse oximetry. Arch Gynecol Obstet. 2002;266(2):105-7. doi: $10.1007 /$ s00404-001-0272-5.

Source of Support: Nil, Conflict of Interest: None declared 